DOI: 10.46340/eujem.2021.7.6.2

\author{
Alina Polukhina, PhD in Political Science \\ ORCID ID: http://orcid.org/0000-0002-3475-448X

\section{FEATURES OF THE ORGANIZATION \\ OF DISTANCE LEARNING \\ IN HIGHER EDUCATION INSTITUTIONS}

\author{
Аліна Полухіна, к. політ. н. \\ ОСОБЛИВОСТІ ОРГАНІЗАЦІї \\ ДИСТАНЦІЙНОГО НАВЧАННЯ \\ У ЗАКЛАДАХ ВИЩОЇ ОСВІТИ
}

The article is devoted to the analysis and identification of the features of distance learning in higher education institutions. It is noted that the introduction of distance learning systems in the educational process is an urgent task, which solution will allow the training of competent professionals ready to perform the full range of professional functions; when implementing distance learning systems in the educational process, it is advisable to use a single digital platform that takes into account the requirements of state educational standards.

Such positive aspects of distance learning as low cost of training, flexible training schedule, possibility of in-service training and possibility of continuous training proved to be irrelevant for forced self-isolation. We continue to consider the use of information technology, the availability of educational material and manufacturability as an indisputable advantage of distance learning. We need a critical assessment of the distance learning experience to identify prospects for the use of distance learning technologies in both classroom practice and a variety of online forms of teacher-student interaction.

It is important to note that the main problem for students in relation to independent work is the lack of knowledge and skills of organizing independent learning activities. Therefore, the strategy of performing tasks offered to students as independent work should be carefully considered by the teacher.

Keywords: distance learning, students, e-learning, Higher Education Institution, Internet technologies, interactive methods.

Постановка проблеми. В умовах пандемії COVID-19 та введення карантинних обмежень призвело до перегляду методів та підходів, які раніше застосовувалися під час навчального процесу в закладах вищої освіти (далі - 3ВО). Запровадження дистанційного навчання - нова реальність сучасної освіти, зокрема вищої. Впроваджено навчання за допомогою інтерактивних методів аудіовізуальних програм (наприклад, Zoom, YouTube, Skype, Viber і т.п.). Наказ МОН України від 25.04.2013 р. № 466 зі змінами № 1115 від 08.09.2020 р. визначає дистанційне навчання як: «індивідуалізований процес набуття знань, умінь, навичок і способів пізнавальної діяльності людини, який відбувається в основному за опосередкованої взаємодії віддалених один від одного учасників навчального процесу у спеціалізованому середовищі, яке функціонує на базі сучасних психолого-педагогічних та інформаційно-комунікаційних технологій» ${ }^{1}$. Однак, система вищої освіти України та більшість країн світу загалом зіткнулись з проблемою реалізації дистанційного навчання в надзвичайних умовах. Актуальність використання дистанційного навчання на даний час не викликає сумнівів.

Аналіз останніх досліджень та публікацій. Дослідженням проблеми організації дистанційного навчання у закладах вищої освіти займалися наступні вчені: Ю. Гавронська,

\footnotetext{
${ }^{1}$ Наказ про затвердження Положення про дистанційне навчання 2013 (Міністерство освіти і науки України). Офіиійний сайт Верховної Ради Украӥни. <https://zakon.rada.gov.ua/laws/show/z0703-13\#Text>.

(2021, листопад, 28).
} 
М. Г. Голубчикова, Г. П. Григор’єв, Н. Ю. Гутарєва, О. М. Крайнов, Е. Розетт, А. Г. Сергєєв, Н. Я. Червова та інші.

Метою статті $є$ аналіз та виявлення особливостей дистанційного навчання у закладах вищої освіти.

Виклад основного матеріалу. Одним із напрямків розвитку системи вищої освіти $\epsilon$ створення сучасного та безпечного цифрового освітнього середовища, що забезпечує впровадження нових методів навчання, освітніх технологій, у тому числі дистанційного навчання, актуальність якого останнім часом стала особливо очевидною. При цьому дистанційне навчання може формуватися як доповнення до традиційних форм освітнього процесу, так і виступати у вигляді закінченої самодостатньої системи, що реалізує основні вимоги до технології та якості навчання.

Практичний досвід вивчення питання дистанційного навчання показав успішність переходу на режим електронного навчання та використання дистанційних освітніх технологій. Організація навчального процесу при цьому здійснювалася або на спеціалізованих цифрових платформах або 3 використанням різноманітних ресурсів (MOODLE, GOOGLE, ZOOM, Watsapp, та ін.) ${ }^{1}$.

Проте, як показав аналіз, науково-педагогічний склад повною мірою мають необхідні компетенції в галузі сучасних технологій онлайн-навчання. Проте деяким необхідне додаткове навчання у різних формах - курси підвищення кваліфікації, спеціалізовані семінари-практикуми, консультації фахівців. Тому, одним із актуальних завдань є розробка методики формування дистанційних програм вивчення дисциплін професійного циклу.

Для забезпечення ефективності навчального процесу в сучасних освітніх технологіях має реалізовуватись комплекс із трьох взаємопов'язаних складових:

змістовна частина, що передається студентам, повинна припускати не лише освоєння предметних знань, а й розвиток відповідних компетенцій;

застосовувані методи навчання повинні грунтуватися не на пасивному сприйнятті матеріалу, а на залученні студентів у навчальний процес та їх активну взаємодію з викладачем;

використовувана інфраструктура навчання повинна включати взаємопов'язані технологічну, інформаційну, організаційну та комунікаційну складові. У цьому можна виділити низку актуальних інноваційних методів навчання, у яких можуть бути представлені перелічені складові освітнього процесу: проведення тренінгових практичних занять; моделювання професійної діяльності у навчальному процесі; ігрове імітаційне моделювання та ін. ${ }^{2}$

Варто зазначити, що впровадження систем дистанційного навчання в освітній процес $\epsilon$ актуальним завданням, вирішення якого дозволить підготовку компетентних фахівців, готових до здійснення повного спектру професійних функцій; при впровадженні систем дистанційного навчання в освітній процес доцільно використати єдину цифрову платформу, що враховує вимоги державних освітніх стандартів ${ }^{3}$.

Дистанційне навчання сприяє розвитку навчальної самостійності студентів. Самостійність як форма інтелектуальної діяльності визначає розвиток навичок планування, самоконтролю та самооцінки. Розвиток цих навичок передбачає знання загальних правил, яким чином слід діяти в ситуаціях навчального процесу, що задаються, а далі - і в ситуаціях професійної сфери ${ }^{4}$.

Навчальна самостійність студентів дозволяє здійснити перехід до індивідуалізації навчання, що забезпечує максимальну залученість студентів до навчального процесу, сприяє зростанню рівня мотивації5.

\footnotetext{
${ }^{1}$ Крайнов, А.Н., Панов, Н.А. (2020). Актуальные аспекты использования систем дистаниионного обучения в образовательном проиессе. <https://cyberleninka.ru/article/n/aktualnye-aspekty-ispolzovaniya-sistemdistantsionnogo-obucheniya-v-obrazovatelnom-protsesse>. (2021, листопад, 26).

${ }^{2}$ Крайнов, А.Н., Панов, Н.А. (2020). Актуальные аспекты использования систем дистанционного обучения в образовательном прочессе. <https://cyberleninka.ru/article/n/aktualnye-aspekty-ispolzovaniya-sistemdistantsionnogo-obucheniya-v-obrazovatelnom-protsesse>. (2021, листопад, 26).

${ }^{3}$ Крайнов, А.Н., Панов, Н.А. (2020). Актуальные аспекты использования систем дистанционного обучения в образовательном прочессе. <https://cyberleninka.ru/article/n/aktualnye-aspekty-ispolzovaniya-sistemdistantsionnogo-obucheniya-v-obrazovatelnom-protsesse>. (2021, листопад, 26).

${ }^{4}$ Голубчикова, М.Г. (2020). Теоретический анализ понятия «самостоятельность» в историческом и современном аспектах. Мир науки, культуры, образования, 1 (80), 37.

${ }_{5}^{5}$ Роззетт, Э., Фрази, Р.В. (2006). Возможности смешанного обучения. E-Learning World, 1, 2-6.
} 
Індивідуалізація передбачає самостійну активність студента, спрямовану на оволодінні знаннями. Студент сам визначає час та швидкість виконання завдань методичних матеріалів. Однак, якщо інтерактивні навчальні курси пропонують рівневу модель вивчення матеріалу, то методичні матеріали, представлені на освітньому порталі, не становлять жорсткої градації за рівнем вивчення.

Доцільно здійснити актуалізацію матеріалів та внести позначку рівня кожного завдання у навчальному посібнику/збірнику завдань для того, щоб сформувати обсяг виконання завдань з урахуванням індивідуального рівня підготовки студентів. Безсумнівно, ця проблема вирішується при взаємодії з викладачем, проте наявність певного маркера у завданні дозволяє заощадити час і викладача, і студента. Як зазначається вище, індивідуалізація передбачає постійну взаємодію студента з викладачем.

Дистанційний формат навчання, який сьогодні обрано як основне, обумовлює організацію діяльності викладача таким чином, щоб студент мав можливість отримання відповіді та консультації у разі неможливості або утруднення виконання завдання. Здійснення постійного контакту зі студентами має реалізовуватись на основі сформованого індивідуального графіка. 3 іншого боку, індивідуалізація не сприймається як безконтрольність. Своєчасність перевірки виконаних студентами завдань та коментар викладача 3 робіт студентів формує в студентів розуміння зацікавленості викладача в результаті оволодіння дисципліни студентами. Безсумнівно, що студенти найбільш мотивовані, якщо вони отримують моментальний зворотний зв'язок'

У зв'язку з цим найефективнішими є завдання, створені в автоматизованій системі, що дозволяють студенту багаторазове виконання завдання до досягнення позитивного результату. Завдання, створені із застосуванням автоматизованої системи навчання, дозволяють студенту власним досвідом виявити помилку. Однак, як правило, основна маса таких вправ представляє завдання вибору однієї правильної відповіді з декількох, завдання на співвідношення терміна з визначенням/частин пропозиції, позиційне визначення ділянки інформації до змісту тексту. Коментар викладача в даному випадку можливий лише при розвантаженні всієї роботи студента, що часто вимагає додаткового часу на взаємодію 3 працівниками, які займаються автоматизованою системою. Завдання даного типу можуть успішно використовуватись для закріплення знань.

Слід зазначити, що існує позиція, згідно $з$ якою дистанційна форма навчання повинна розглядатися як освітня парадигма, оскільки даний підхід представляє «добре продумане інтерактивне середовище навчання будь-якому студенту, в будь-якому місці і в будь-який час, використовуючи ресурси різних цифрових технологій поряд 3 іншими формами навчальних матеріалів, що підходять для відкритого середовища навчання. E-learning здійснює перехід від системи управління даними до системи управління знаннями» ${ }^{2}$.

Незважаючи на те, що на даний момент основна маса студентів очної форми навчання перейшла на дистанційний формат вивчення дисциплін, слід зазначити можливості використання Інтернет-ресурсів для організації самостійної роботи студентів. Саме у процесі самостійної роботи студент стає активним учасником навчального процесу. Самостійність передбачає свідоме ставлення студента до пізнання теоретичних аспектів та оволодіння практичними навичками 3 вивчення дисциплін.

Важливо відзначити, що основною проблемою для студентів щодо самостійної роботи $\epsilon$ відсутність знань та вмінь організації самостійної навчальної діяльності. Тому стратегія виконання завдань, запропонованих студентам як самостійна робота, повинна ретельно продумуватися викладачем. Етапи виконання завдання самостійної роботи повинні розвивати навички студента до планування дій задля досягнення мети завдання, визначення тимчасових витрат за кожен етап виконання завдання. Обов'язковим є постійне курування викладачем виконання кожного етапу завдання.

\footnotetext{
1 Червова, Н.Я. (2014). Возможности e-learning в процессе изучения иностранного языка. Социогуманитарный вестник Кемеровского института (филиала) РГТЭУ, 1 (13).

<http://vuzirossii.ru/publ/vozmozhnosti_e_learning_v_processe_izuchenija_inostrannogo_jazyka/15-1-0-3417>. (2021, листопад, 29).

${ }^{2}$ Сергеев, А.Г., Жигалов, И.Е., Баландина, В.В. (2012). Введение в электронное обучение. Владимир:

Издательство ВлГУ, 9.
} 
Метод проектної діяльності найбільш успішно може застосовуватися як завдання самостійної роботи студентів. Безсумнівно, що підготовка даного виду роботи є трудомістким процесом, оскільки викладачеві необхідно здійснити пошук відповідних ресурсів, розробити завдання в рамках робочої програми дисципліни, виробити стратегію роботи студента 3 даним ресурсом, алгоритм отримання цільової інформації, ії обробку для представлення групі з урахуванням подальшого обговорення. Метод проектів сприяє як зростанню іншомовних компетенцій студента, а й дозволяє розширити межі загального інтелектуального розвитку, викликає активізацію навчальної діяльності студентів.

В результаті роботи над проектом студенти успішно можуть поєднувати вже сформовані іншомовні компетенції з набуттям нових знань за запропонованою тематикою. Слід зазначити, що виконання завдань 3 використанням Інтернет-ресурсів має бути обумовлено: зростанням рівня мотивації, пов'язаного безпосередньо з виконанням такого завдання, що визначається фокусуванням усієї діяльності студента на кінцевий результат виконання завдання; усвідомлення студентом сутності змісту та виконання завдання (це безпосередньо залежить від того, наскільки чітко та ясно будуть сформульовані ціль та завдання виконання завдання викладачем, визначено форму перевірки та оцінки, терміни подання матеріалу); в) реалізація студентом творчого елемента самостійної роботи (викладач виступає як координатор пізнавальної діяльності студентів).

При виконанні такого виду самостійної роботи найбільш явно проявляється наявність мотивації студента до вивчення навчальних дисциплін, оскільки виконання такого завдання потребує часу на пошук інформації, iіi аналіз та переробку для подання у відповідному форматі. Така робота вимагає готовності студента до роботи з довідковою літературою, різними словниками та використанням засобів інформаційно-комунікаційних технологій для здійснення цілеспрямованої діяльності 3 пошуку інформації та ії подання.

Визначаючи характерні риси дистанційної форми у ЗВО, наголошується на опосередкованому характері комунікативної взаємодії «викладач - студент», яка реалізується за допомогою засобів інформаційно-комунікаційних технологій. I якщо, з одного боку, відбувається скорочення обсягу безпосередньої комунікативної взаємодії суб'єктів навчального процесу, з іншого боку, дана форма навчання дозволяє значною мірою активізувати самостійну роботу. Навички самостійної роботи $€$ найбільш актуальними в даний час з урахуванням вимог ринку, оскільки сучасний професіонал має вміти планувати та організовувати діяльність щодо вирішення конкретного завдання ${ }^{1}$.

При реалізації навчання у дистанційному форматі зберігається сутність електронного навчання, що характеризується інтерактивністю взаємодії студента зі студентом та індивідуалізацією навчання, що базується на впровадженні навчально-методичного комплексу, створеного в електронному форматі» ${ }^{2}$. Для студентів цього покоління персональні комп'ютери, доступ, пошук та вилучення інформації в Інтернеті $є$ реаліями їхнього повсякденного життя» ${ }^{3}$. Сам уклад сучасного життя висуває вимогу оптимального впровадження засобів інформаційно-комунікаційних технологій у навчальному процесі для того, щоб викладач міг доносити навчальну інформацію, а студент сприймати та засвоювати іiї, використовуючи дані засоби. Тобто викладач має не лише розвивати студентів, а й розвиватись сам. Незважаючи на актуальність дистанційного формату навчання за нинішніх умов та ефективність застосування автоматизованих систем навчання, дана форма навчання не може розглядатися повноцінною альтернативою очної форми навчання.

Варто також відзначити, що є загрози, пов'язані з переходом на дистанційний формат: спад мотивації студентів до навчання; нестача у студентів навичок та умінь для підтримки дисципліни та старанності у дистанційному навчанні; зростання навантаження на викладачів; відсутність у системі освіти індивідуального підходу, знеособленість; неможливість контролювати рівень знань; обмеження у ряді напрямків (насамперед, технічних, математичних) на дистанційну передачу знань; формалізація процесів освіти, схильність до шаблонних, уніфікованих рішень ${ }^{4}$.

\footnotetext{
${ }^{1}$ Гутарева, Н.Ю. (2006). Дистанционное обучение иностранным языкам в неязыковом вузе. Вестник ТГПУ. Серия: Гуманитарные науки (Филология), 4 (55), 190.

${ }^{2}$ Гавронская, Ю. (2018). «Интерактивность» и «интерактивное обучение». Высшее образование в России, 7 , 101-104.

${ }^{3}$ Роззетт, Э., Фрази, Р.В. (2016). Возможности смешанного обучения. E-Learning World, 1, $2-6$.

${ }^{4}$ Григорьев, Г.П., Рудакова, О.А. (2021). Актуальные проблемы дистанционного обучения: психологический аспект. <https://cyberleninka.ru/article/n/aktualnye-problemy-distantsionnogo-obucheniya-psihologicheskiy-aspekt>. (2021, листопад, 26).
} 
Аналіз психолого-педагогічних аспектів дистанційної освіти, у тому числі на основі результатів емпіричних досліджень студентів, показав: можливості та перспективи розвитку інформаційноосвітнього середовища вузу при навчанні студентів, важливість використання змішаної форми дистанційного та очного навчання, наявність індивідуалізації освітнього процесу, необхідність обліку запитів студентів та цілей професійної освіти при використанні дистанційних технологій, забезпечення у позитивному мотиваційно-емоційному середовищі взаємодії викладачів та студентів, можливість підвищення мотивації студентів до навчання в умовах дистанційної освіти, розширення можливостей при організації комунікації, взаємодії зі студентом при вивченні ними дистанційного курсу, організацію психолого-педагогічного супроводу студентів в умовах дистанційного навчання, у тому числі різних категорій (студенти 3 обмеженими можливостями здоров'я та інвалідністю), формування психологічної готовності викладачів та студентів до розширення освітніх можливостей 3 використанням дистанційних технологій (моніторинг, психолого-педагогічна підтримка суб'єктів освітнього процесу та ін. $)^{1}$.

Висновки. Підсумовуючи вищесказане, можна зробити висновок, що сьогодні актуальною $€$ проблема необхідності підвищення кваліфікації викладачів вузів, зумовлена мінливими тенденціями та вимогами впровадження інноваційних технологій. Крім того, «положення про атестацію працівників на відповідність кваліфікації викладача займаної посади» викликало різку необхідність підвищення кваліфікації або перекваліфікації серед викладачів вузів. Можна зробити висновок, що в цих складних для викладача умовах дистанційна форма навчання як «навчання без відриву від виробництва та без фізичного переміщення до місця розташування установи» $\epsilon$ найбільш ефективною та затребуваною. Визначено, що цифрова революція в освіті - тема не нова, і при цьому ті 3ВО, які готувалися до неї, сприймають нову реальність легше. Сьогодні легше буде тим освітнім організаціям, які зможуть створити та реалізувати моделі, що дозволяють прогнозувати активність студентів онлайн-курсів, моделі, що дозволяють відслідковувати активність студента всередині курсу - наприклад, чи перегляне він відеолекцію, та чи прочитає необхідний матеріал.

\section{References:}

1. Gavronskaja, Ju. (2018). «Interaktivnost'» i «interaktivnoe obuchenie» ["Interactivity" and "interactive learning"]. Vysshee obrazovanie v Rossii [Higher education in Russia], no. 7, 101-104. [in Russian].

2. Golubchikova, M.G. (2020). Teoreticheskij analiz ponjatija «samostojatel'nost'»v istoricheskom i sovremennom aspektah [Theoretical analysis of the concept of "independence" in the historical and modern aspects]. Mir nauki, kul'tury, obrazovanija [The world of science, culture, education], no. 1 (80), 35-38. [in Russian].

3. Grigor'ev, G.P., Rudakova, O.A. (2021). Aktual'nye problemy distancionnogo obuchenija: psihologicheskij aspekt [Actual problems of distance learning: psychological aspect]. 〈https://cyberleninka.ru/article/n/aktualnye-problemy-distantsionnogo-obucheniya-psihologicheskiy-aspekt > . (2021, November, 26). [in Russian].

4. Gutareva, N.Ju. (2006). Distancionnoe obuchenie inostrannym jazykam v nejazykovom vuze [Distance learning of foreign languages in a non-language university]. Vestnik TGPU. Serija: Gumanitarnye nauki (Filologija) [Bulletin of TSPU. Series: Humanities (Philology)], iss. 4 (55), 189-192. [in Russian].

5. Krajnov, A.N., Panov, N.A. (2020). Aktual'nye aspekty ispol'zovanija sistem distancionnogo obuchenija v obrazovatel'nom processe [Actual aspects of using distance learning systems in the educational process]. $<$ https://cyberleninka.ru/article/n/aktualnye-aspekty-ispolzovaniya-sistem-distantsionnogo-obucheniyav-obrazovatelnom-protsesse>. (2021, November, 26). [in Russian].

6. Nakaz pro zatverdzhennia Polozhennia pro dystantsiine navchannia 2013 [Order approving the Regulation on distance learning] (Ministerstvo osvity i nauky Ukrainy) [(Ministry of Education and Science of Ukraine)]. Ofitsiinyi sait Verkhovnoi Rady Ukrainy [Official site of the Verkhovna Rada of Ukraine]. 〈https://zakon.rada.gov.ua/laws/show/z0703-13\#Text>. (2021, November, 28). [in Ukrainian].

7. Rozzett, Je., Frazi, R.V. (2006). Vozmozhnosti smeshannogo obuchenija [Blended learning opportunities]. E-Learning World, no. 1, 2-6. [in Russian].

8. Sergeev, A.G., Zhigalov, I.E., Balandina, V.V. (2012). Vvedenie v jelektronnoe obuchenie [Introduction to eLearning]. Vladimir: Izdatel'stvo VlGU. [in Russian].

\footnotetext{
${ }^{1}$ Шалагинова, К.С., Декина, Е.В. (2020). Психолого-педагогические аспекты дистанционного образования в условиях пандемии: по материалам анкетирования студентов - будущих психологов. Психолого-педагогические исследования, 12, 3, 80-94.
} 
9. Chervova, N.Ja. (2014). Vozmozhnosti e-learning v processe izuchenija inostrannogo jazyka [Opportunities for e-learning in the process of learning a foreign language]. Sociogumanitarnyj vestnik Kemerovskogo instituta (filiala) RGTJeU [Socio-Humanitarian Bulletin of the Kemerovo Institute (branch) of the RGTEU], no. 1 (13). <http://vuzirossii.ru/publ/vozmozhnosti_e_learning_v_processe_izuchenija_inostrannogo_jazyka/15-1-0-3417>. (2021, November, 29). [in Russian].

10. Shalaginova, K.S., Dekina, E.V. (2020). Psihologo-pedagogicheskie aspekty distancionnogo obrazovanija $\mathrm{v}$ uslovijah pandemii: po materialam anketirovanija studentov - budushhih psihologov [Psychological and pedagogical aspects of distance education in a pandemic: based on the materials of a survey of students future psychologists]. Psihologo-pedagogicheskie issledovanija [Psychological and pedagogical research], vol. 12, no. 3, 80-94. [in Russian]. 